\title{
Leonardo Funes (coord.), Hispanismos del mundo. Diálogos y debates en ( $y$ desde) el Sur, Buenos Aires, Miño y Dávila, 2016, 384 pp. y CD-ROM
}

Calabrese, Martín

Instituto de Investigaciones en Humanidades y Ciencias Sociales (IdIHCS) - Universidad Nacional

de La Plata -CONICET, Argentina 


\title{
Leonardo Funes (coord.), Hispanismos del mundo. Diálogos y debates en (y desde) el Sur, Buenos Aires, Miño y Dávila, 2016, 384 pp. y CD-ROM
}

\author{
Martin Calabrese \\ Instituto de Investigaciones en Humanidades y Ciencias \\ Sociales (IdIHCS) - Universidad Nacional de La Plata - \\ CONICET, Argentina
}

El congreso celebrado en la ciudad de Buenos Aires fue de suma importancia debido a que fue el primero en realizarse en el Hemisferio Sur, saldando de algún modo la deuda de la AIH con nuestras latitudes. Después del congreso realizado en México (1968) los hispanistas de todo el mundo esperaban que fuera la Ciudad de Buenos Aires la sede del evento. A pesar de los avatares políticos y económicos atravesados por el país, finalmente en el año 2016 pudo realizarse.

La inauguración del congreso y su presentación estuvo a cargo de Melchora Romanos, Presidenta de la Comisión Local Organizadora; Aldo Ruffinatto, Presidente de la Asociación Internacional de HIspanistas y Laura Scarano, Presidenta de la Asociación Argentina de HIspanistas.

En los seis días que duró el congreso 426 estudiosos, de diversas trayectorias, compartieron los resultados de sus trabajos e investigaciones, de los cuales alrededor de un $60 \%$ decidieron publicar en la presente edición, que cuenta con una treintena de trabajos, agrupado bajo los siguientes apartados: "Conferencias plenarias" (las mismas ofrecen un nutrido panorama de temáticas y abordajes sobre los cuales versaron las diferentes mesas de ponencias, a saber, literatura medieval, literatura del Siglo de Oro, edición contemporánea, diversos soportes de la ficción); dos paneles sobre "El arte de novelar cervantino", que cuenta con ponencias de reconocidos autores locales e internacionales; dos apartados dedicados a celebrar las décadas de labor hispanista en nuestro país: "Los noventa años del instituto Amado Alonso y la vigencia de la Filología en Argentina"; "Nuevas perspectivas en los estudios hispanomedievales: celebrando los 40 años de La Crónica"; "Cortázar a los 50 años de Rayuela".

A su vez, durante el congreso se llevó a cabo el encuentro entre los presidentes de las diferentes Asociaciones Nacionales de Hispanistas que reunió a presidentes de 11 naciones. El resultado de dicha reunión quedó asentado en este volumen y se da cuenta allí de las propuestas que se consideran como norte para el hispanismo:

1. Creación de una página web.

2. Creación de un boletín informativo, con el título Nuevo Hispanismo.

3. Registro bibliográfico que se enviará a la Fundación Biblioteca Virtual Miguel de Cervantes.

4. Apoyo a las asociaciones nacionales emergentes con la creación de infraestructura, y respaldo a la libre circulación de alumnos e investigadores.

5. Realización de encuentros similares al presente.

La grata experiencia vivida en el encuentro y la afinidad de diversos estudiosos de los más diversos lugares del Planeta, dan cuenta de lo heterogéneo de la hispanidad, de la variedad de intereses, objetivos y modos de abordaje de la materia literaria y lingüística hispana. Nos encontramos en este libro con el reflejo de la variedad de hispanismos que coexisten, muchas veces en ámbitos distantes, y otras tantas en fronteras que se acercan y desdibujan. 
A lo largo de los días del congreso se han llevado a cabo también encuentros entre diferentes investigadores que sirvieron para presentar proyectos e investigaciones de reluciente vigencia y actualidad. En estos encuentros, coordinados por reconocidos especialistas, han abordado los ejes troncales de las investigaciones hispanistas. El primero de ellos, coordinado por Hugo Bizzarri y Aengus Ward, titulado "Literatura española. Edad Media" ha servido como espacio de presentación del proyecto de Humanidades Digitales ReMetCa, presentado por Elena González-Blanco Garcia y Gimena del Río Grande, que nuclea un repertorio métrico digital de la poesía medieval castellana.

Las temáticas de estos encuentros abordaron también la "Literatura española. Siglo de Oro", encuentro coordinado por Fernando Copello e Isabel Pérez Cuenca. "Literatura española moderna y contemporánea", a cargo de Gladys Granata de Egües y Laura Scarano. "Literatura latinoamericana colonial", que contó en su cordinación a Blanca López de Mariscal y Sonia V. Rose. "Literatura latinoamericana contemporánea", coordinado por Rose Corral, Ángeles Mateo del Pino y María Alejandra Torres. "Teoría e historias literarias", presidido por Luis Beltrán Almería y Miguel ängel Garrido Gallardo. Por último, el encuentro dedicado a "Lengua y lingüística", coordinado por Jairo Javier García Sanchez y Elisabetta Paltrinieri.

El ejemplar impreso además, cuenta con una versión digital y con material complementario muy provechoso en un CD que acompaña la edición. 